\title{
Akt Regulated Phosphorylation of GSK-3 $\beta /$ Cyclin D1, p21 and p27 Contributes to Cell Proliferation Through Cell Cycle Progression From G1 to S/G2M Phase in Low-Dose Arsenite Exposed HaCat Cells
}

\author{
Yao Chen, Xudan Liu, Huanhuan Wang, Shiyi Liu, Nannan Hu and Xin Li* \\ Department of Occupational and Environmental Health, Key Laboratory of Arsenic-related Biological Effects and Prevention \\ and Treatment in Liaoning Province, School of Public Health, China Medical University, Shenyang, China
}

\section{OPEN ACCESS}

Edited by:

Eleonore Fröhlich,

Medical University of Graz,

Austria

Reviewed by:

Ekhtear Hossain,

Louisiana State University,

United States

Piyajit Watcharasit,

Chulabhorn Research Institute,

Thailand

${ }^{*}$ Correspondence:

$X$ in $\mathrm{Li}$

xli75@cmu.edu.cn

Specialty section: This article was submitted to

Predictive Toxicology,

a section of the journal

Frontiers in Pharmacology

Received: 10 May 2019 Accepted: 12 September 2019

Published: 11 October 2019

Citation:

Chen Y, Liu X, Wang H, Liu S, Hu N and Li X (2019) Akt Regulated

Phosphorylation of GSK-3//Cyclin

D1, p21 and p27 Contributes to Cell Proliferation Through Cell Cycle

Progression From G1 to

S/G2M Phase in Low-Dose Arsenite

Exposed HaCat Cells.

Front. Pharmacol. 10:1176.

doi: 10.3389/fphar.2019.01176
Arsenic is a toxic environmental contaminant. Long-term exposure to arsenic through drinking water induces human cancers. However, it is as yet uncertain about the mechanisms of arsenic induced carcinogenesis. Although the effects of low-dose arsenicals on proliferation and cell cycle have been revealed by short time exposure, the evidences for long-term exposure were seldom reported. The detailed mechanism has been unclear and supplemented constantly. In the present study, we used normal human keratinocytes (HaCat) to study the effects of long-term, low-dose sodium arsenite $\left(\mathrm{NaAsO}_{2}\right)$ exposure on cell proliferation with emphasis on the Akt regulated cell cycle signaling pathways. Treatment of $\mathrm{NaAsO}_{2}$ resulted in increased cell proliferation and promotion of cell cycle progression from G1 to S/G2M phase, both of which could be attenuated by MK2206, a highly selective inhibitor of Akt. Along with the increased expression of phospho-Akt ( $p$-Akt, Ser 473), increased expression of $p$-GSK-3 $\beta$ (Ser 9), p-p21 (Thr 145), p-p27 (Thr 157) and total cyclin D1, and decreased expression of $p$-cyclin D1 (Thr 286), p21 and p27 were also found in the $\mathrm{NaAsO}_{2}$ exposed cells. Treatment of MK2206 markedly reversed the expression of all of the above proteins. Our findings indicated that the phosphorylated activation of Akt played a role in the proliferation of HaCat cells upon long-term, low-dose $\mathrm{NaAsO}_{2}$ exposure through the phosphorylative regulation of its downstream cell cycle regulating factors of GSK-3//cyclin D1, p21 and p27, which could induce the promotion of cell cycle progression from G1 to S/G2M phase.

Keywords: arsenite, Akt, $p$-GSK-3ק, p-cyclin D1, p-p21, p-p27

\section{INTRODUCTION}

Arsenic is a metalloid widely distributed throughout the earth. The main exposure sources of humans include environment and occupation, as well as medicinal arsenical use. As a natural groundwater contaminant, the main source of human environmental exposure is through consumption of groundwater rich in arsenic. Chronic exposure of arsenic via drinking water and its adverse health impacts on humans have been a worldwide health issue in the recent decades (Rahman et al., 2009). It is estimated that nearly 200 million people throughout the 
world are at risk of toxic exposure to arsenic, nowadays (Hunt et al., 2014). Groundwater used for drinking contaminated by arsenic was first recognized in the 1960s in China and has been a health threat since then. According to a recent report from Science, nearly 19.6 million people are reported to be at risk of arsenic-related adverse health injuries through the consumption of arsenic-contaminated groundwater in China (Rodríguez-Lado et al., 2013).

Arsenic is a well-known human carcinogen confirmed by the International Agency for Research on Cancer (IARC). Chronic exposure to arsenic through drinking water has been reported to be associated with cancers including skin, bladder, kidney, liver, and lung (IARC Working Group on the Evaluation of Carcinogenic Risk to Humans, 2004; Celik et al., 2008; Saint-Jacques et al., 2014; Wang W., et al., 2014; Karagas et al., 2015). Among them, skin is believed to be the most sensitive site, therefore, skin cancer is regarded as an early malignancy due to arsenic exposure (Yu et al., 2006). Although high levels of arsenic exposure through drinking water is considered to be associated with the occurrence of arsenic-related cancers, evidences about exposures at relatively lower levels, i.e. less than $100 \mu \mathrm{g} / \mathrm{L}$, are inconsistent (Cohen et al., 2013). There are increasing evidences suggesting that arsenic-related skin lesions and skin cancers can be induced at levels which are not regarded as harmful previously (Karagas et al., 2015).

Keratinocytes are believed to be the main target cells in arsenic-induced skin carcinogenesis. A concentrationdependent cellular response was observed in keratinocytes exposed to arsenic, which is demonstrated by apoptosis induced by high-dose exposure and proliferation induced by low-dose exposure. Long-term arsenic exposure induced keratinocyte proliferation is possibly involved in the process of skin carcinogenesis (Liao et al., 2011).

Many intracellular signaling pathways were involved in the arsenic induced skin cancer including Akt (Hunt et al., 2014). Akt is a central regulator which play an important role in the regulation of cell metabolism, cell cycle, and apoptosis (Hanada et al., 2004; Sale and Sale, 2008). Relatively high expression or phosphorylation of Akt could be found in many tumor cells including arsenic-related cancers (Carpenter and Jiang, 2013; Cheung and Testa, 2013). Activation of Akt induced by arsenic exposure was also reported in cultured human keratinocytes (Souza et al., 2001). Since the Akt regulated signals are a complicated network system, the detailed signaling pathways involved in arsenic induced carcinogenesis remain to be elucidated.

Although the effects of arsenicals on proliferation and cell cycle have been revealed by short time exposure, the evidences for long-term, low-dose exposure were seldom reported. In the present study, we exposed human keratinocytes (HaCat) to low-dose $\mathrm{NaAsO}_{2}$ for 15 weeks and focused on the Aktregulated cell cycle signals of glycogen synthase kinase $3 \beta$

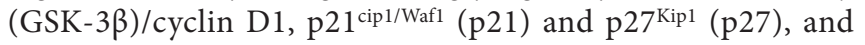
discussed the possible role of the phosphorylative activation of Akt and the consequent phosphorylation of its downstream cell cycle regulating factors in the proliferation of low-dose $\mathrm{NaAsO}_{2}$ exposed HaCat cells.

\section{MATERIALS AND METHODS}

\section{Reagents}

Sodium arsenite $\left(\mathrm{NaAsO}_{2}, \geq 90 \%\right)$, dimethyl sulfoxide (DMSO), and ribonuclease A (RNase A) were purchased from SigmaAldrich, USA. MK2206 ( $\geq 99.91 \%)$, a highly selective inhibitor of Akt was purchased from Selleck Chemicals, USA. CellTiter 96 was purchased from Promega, USA. Trypsin, fetal bovine serum (FBS), and minimum essential medium (MEM) were purchased from Thermo Scientific, USA. Protease inhibitor cocktail was purchased from Roche, Germany. Phosphorylase inhibitor P1260 was purchased from Applygen Technologies Inc, Beijing, China. Antibodies specific targeting $p$-GSK-3 $\beta$ (Ser9, sc-81494), p-p21 (Thr145, sc-377569), cyclin D1 (sc-246), and $\beta$-actin (sc47778) were purchased from Santa Cruz Biotechnology, USA. Antibodies against $p$-Akt (Ser473, \#9271), Akt (\#4685S), GSK-3 $\beta$ (\#5676), p-cyclin D1 (Thr286, \#3300), p21 (\#2947), p27 (\#3686), and MMP9 (\#13667) were purchased from Cell Signaling Technology, USA. Antibody of p-p27 (Thr157, ab85047) was purchased from Abcam, China.

\section{Cell Culture and Arsenic Treatment}

$\mathrm{HaCat}$ was purchased from the cell bank of Chinese Academy of Medical Sciences. Cells were grown in MEM supplemented with $10 \%$ FBS and antibiotics in a humidified incubator with $5 \% \mathrm{CO}_{2}$ at $37^{\circ} \mathrm{C}$. An aqueous sterile stock solution of $\mathrm{NaAsO}_{2}$ was prepared $(1 \mathrm{mmol} / \mathrm{L})$. Stock solution was diluted to the desired final concentration every time before culture media change. A total of three sets of cells were established. Within each set, cells were continuously exposed to $\mathrm{NaAsO}_{2}$ at the concentration of $0,0.05$, and $0.1 \mu \mathrm{mol} / \mathrm{L}$ for 15 weeks. After 1 week of the first set was established, the second set was established. On the third week, the third set of cells was established. The cultures were detached with trypsin and transferred to new culture flasks twice a week. Cells were continuously cultured for 15 weeks, then were used for the analysis of cell proliferation, wound-healing, cell cycle, and protein expression for each set of cells.

\section{Cell Proliferation Assay}

For each set of the cells, cell proliferation was analyzed by CellTiter 96 assay. Briefly, HaCat cells were cultured in decuplicate wells for every concentration ( $0,0.05$ and 0.1 $\mu \mathrm{mol} / \mathrm{L}) ; 1 \times 10^{4}$ viable cells suspended in $200 \mu \mathrm{l}$ media were added into each well of 96-well plates. The plate was incubated at $37^{\circ} \mathrm{C}$ with $5 \% \mathrm{CO}_{2}$. When the monolayer cells grew to approximately $80-85 \%$ confluence, MK2206 at the final concentration of $10 \mu \mathrm{mol} / \mathrm{L}$ (dissolved in DMSO) was added into five wells of each concentration. Equal volume of DMSO was added into the other five wells as control. After culturing for another $24 \mathrm{~h}$, media of each well was replaced by $100 \mu \mathrm{l}$ media containing CellTiter 96 at the concentration of 1:5 (v/v). Cells were then cultured for another 30 minutes, followed by spectrometric measurement under the wavelength of $490 \mathrm{~nm}$. The results were expressed as cell viability relative to the control (proliferation index). 


\section{Wound-Healing Assay}

Cells were seeded into 6-well plates and allowed to form confluent monolayers. Cell monolayers were scratched using a $200 \mu \mathrm{l}$ pipette tip to create a wound and washed once with phosphate-buffered saline (PBS). Fresh MEM and MEM in desired $\mathrm{NaAsO}_{2}$ concentration were added into the control wells and $\mathrm{NaAsO}_{2}$ treated wells, respectively. MK2206 was added into half of the wells and equal volume of DMSO was added into the other half of the wells. Cells were then cultured for another $48 \mathrm{~h}$. Wound width was monitored over time by microscopy and photographed at 0,24 , and $48 \mathrm{~h}$. The widest and the narrowest widths of each wound were measured. The average width was calculated and regarded as the width of each wound. The final results were obtained from three separate experiments.

\section{Cell Cycle Assay}

Cell preparation was the same with that of the cell proliferation assay. After the treatment of MK2206, cells in the presence or absence of MK2206 were then cultured for another $24 \mathrm{~h}$. The cell cycle was detected by the standard propidium iodide method. Briefly, the treated cells were first trypsinized then fixed with $70 \%$ ethanol at $4^{\circ} \mathrm{C}$ overnight. After being washed twice by PBS, cells were then treated with 100 units $/ \mathrm{ml} \mathrm{RNase} \mathrm{A} \mathrm{at} 37^{\circ} \mathrm{C}$ for $30 \mathrm{~min}$, followed by staining with $50 \mathrm{mg} / \mathrm{ml}$ propidium iodide at $4^{\circ} \mathrm{C}$ for 30 min with protection from light. The cell cycle proportion was determined by flow cytometric analysis (FACSCanto II system, BD, Franklin Lakes, NJ, USA). The data was analyzed by the software of ModFit LT for Windows Version 3.2, Verity Software House, USA.

\section{Western Blot Analysis}

Cells were seeded into sextuplicate dishes. When the monolayer cells grew to approximately $80-85 \%$ confluence, MK2206 at the final concentration of $10 \mu \mathrm{mol} / \mathrm{L}$ (dissolved in DMSO) was added into three dishes. Equal volume of DMSO was added into the other three dishes. After culturing for another $24 \mathrm{~h}$, the treated cells were washed by ice cold PBS twice and extracted with cell lysis buffer $(50 \mathrm{mmol} / \mathrm{L}$ Tris (pH 8.0), $150 \mathrm{mmol} / \mathrm{L} \mathrm{NaCl}, 0.1 \% \mathrm{SDS}, 1 \%$ Nonidet P-40 (NP-40), and $0.5 \%$ sodium deoxycholate) supplemented with Roche protease inhibitor cocktail and phosphorylase inhibitor P1260 according to the manufacturer's instructions. Protein concentrations were measured by a Protein Assay Kit (Bio-Rad, CA, USA) according to the manufacturer's recommendation. Equal amounts of proteins $(30 \mu \mathrm{g})$ were separated by $10 \%$ sodium dodecyl sulfate polyacrylamide gel electrophoresis and transferred to polyvinylidene difluoride membranes (Millipore Corporation, USA) by electroblotting. Blots were probed with the primary antibodies of Akt (1:500),

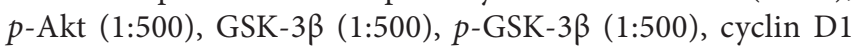
(1:500), p-cyclin D1 (1:500), p27 (1:1000), p-p27 (1:500), p21 (1:1000), $p$-p21 (1:500), MMP9 (1:1000), and $\beta$-actin (1:2000) at $4^{\circ} \mathrm{C}$ overnight, followed by incubation with horseradish peroxidase-conjugated secondary antibodies, respectively. Blots were incubated with chemiluminescence reagents and visualized by Electrophoresis Gel Imaging Analysis System (BioSpectrum Imaging System, USA).

\section{Statistical Analysis}

Data were presented as mean \pm standard deviation (SD). The differences between the treatment of MK2206(-) and MK2206(+) were analyzed by independent-samples $t$ test. The differences of the effects among $\mathrm{NaAsO}_{2}$ concentrations $(0,0.05$ and $0.1 \mu \mathrm{mol} / \mathrm{L}$ ) were analyzed by one-way analysis of variation (ANOVA) followed by Student-Newman-Keuls test or Dunnett's T3 test depending on whether the variances of the data are equal or not. Statistical evaluation of data was performed by the software of SPSS (version 22.0, Chicago, IL). A $p$ value of $<0.05$ was considered as significant.

\section{RESULTS}

\section{Repeated Low-Dose $\mathrm{NaAsO}_{2}$ Exposure Leaded to HaCat Cell Proliferation}

$\mathrm{HaCat}$ cells were repeatedly exposed to $\mathrm{NaAsO}_{2}$ at different concentrations $(0,0.05$ and $0.1 \mu \mathrm{mol} / \mathrm{L})$ for 15 weeks. No morphological alterations were observed in the $\mathrm{NaAsO}_{2}$ exposed cells. The cells looked the same in both the size and shape with those before chronic culture (Figure 1A). The $\mathrm{NaAsO}_{2}$ exposed cells showed an increased proliferative capability while MK2206, a highly selective inhibitor of Akt, significantly decreased the proliferation of $\mathrm{NaAsO}_{2}$ exposed cells (Figure 1B). At the same time, MMP 9, one of the matrix metalloproteinases which is abnormally abundant in the microenvironment during carcinogenesis, was found significantly increased in the $\mathrm{NaAsO}_{2}$ exposed cells. Treatment of MK2206 attenuated the level of MMP9 which indicated the role of Akt in regulating MMP9 activation (Figure 1C).

The wound-healing assay revealed that $\mathrm{NaAsO}_{2}$ exposure increased the wound closure speed after a $24-\mathrm{h}$ incubation. The higher the $\mathrm{NaAsO}_{2}$ concentration, the higher the wound recovery speed (Figure 2A, line 3; Figure 2B). However, $\mathrm{NaAsO}_{2}$ induced increased wound closure was inhibited by the treatment of MK2206 (Figure 2A, line 4; Figure 2B). At the time point of $48 \mathrm{~h}$, all the wounds of cells without MK2206 treatment were closed since the culture time was long enough for wound healing (Figure 2A, line 5). Although wound closure was still inhibited by $\mathrm{MK} 2206, \mathrm{NaAsO}_{2}$ exposed cells showed higher wound-healing capability than that of the control cells (Figure 2B). Cells of the $0.1 \mu \mathrm{mol} / \mathrm{L}$ group showed the highest woundhealing capability (Figure 2A, line 6). These results indicated that repeated low-dose $\mathrm{NaAsO}_{2}$ exposure promoted the proliferation of HaCat cell and that Akt, a central player in the regulation of various physiological functions including cell cycle, was involved in the proliferation induced by low-dose $\mathrm{NaAsO}_{2}$ exposure.

\section{Repeated Low-Dose $\mathrm{NaAsO}_{2}$ Exposure Promoted Cell Cycle Progression From G1 to S/G2M Phase}

Since cell cycle regulation plays an important role in the induction of cell proliferation, we further analyzed the cell cycle 


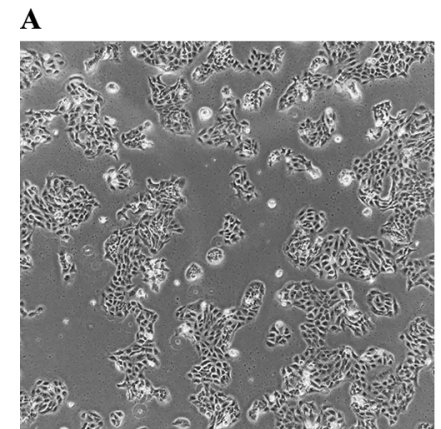

before culture

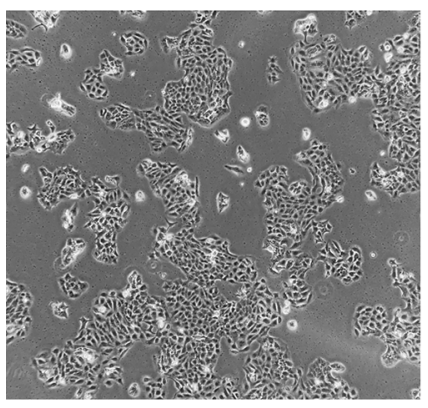

$0.05 \mu \mathrm{M}, 15 \mathrm{w}$

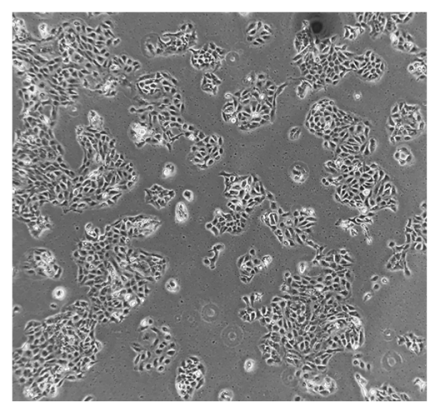

$0 \mu \mathrm{M}, 15 \mathrm{w}$

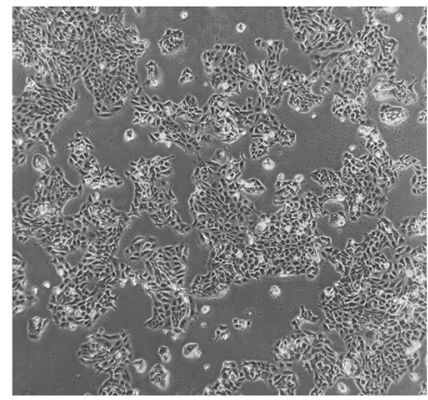

$0.1 \mu M, 15 w$
B

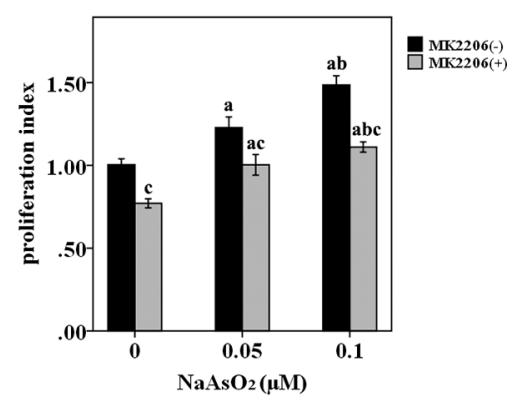

C

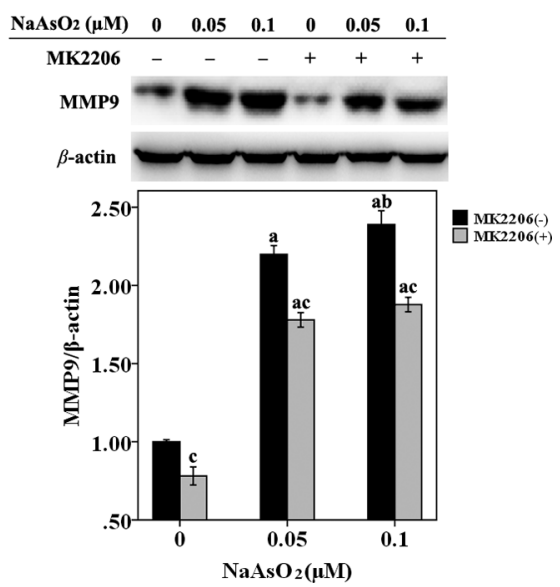

FIGURE 1 | Repeated low-dose $\mathrm{NaAsO}_{2}$ exposure resulted in increased proliferative capability and MMP9 expression in HaCat cell. Cells were continuously exposed to $\mathrm{NaAsO}_{2}$ for 15 weeks at the concentration of 0, 0.05, and $0.1 \mu \mathrm{mol} / \mathrm{L}$. A total of three sets of cells were established. (A) Cell photos taken before longterm culture and after culture for 15 weeks. No morphological alterations were observed in the $\mathrm{NaAsO}_{2}$ exposed cells. (B) For each set of the cell, cell proliferation was analyzed by CellTiter 96 assay. Similar results were obtained from the three sets of cells. A representative figure was presented. The NaAsO ${ }_{2}$ exposed cells showed increased proliferative capability, which could be attenuated by MK2206 (10 $\mu \mathrm{mol} / \mathrm{L}, 24 \mathrm{~h})$. (C) The expression of MMP9 was analyzed by Western Blot assay. Long-term $\mathrm{NaAsO}_{2}$ exposure resulted in increased expressions of MMP9 in the HaCat cells, which could be attenuated by the treatment of MK2206 (10 $\mu \mathrm{mol} / \mathrm{L}, 24 \mathrm{~h}$ ). Significant difference was defined as $p$ less than 0.05 . a, vs. the corresponding $0 \mu \mathrm{M}$ group; b, vs. the corresponding $0.05 \mu \mathrm{M}$ group; $\mathrm{c}$, vs. the MK2206(-) group of the same $\mathrm{NaAsO}_{2}$ concentration.

distribution in this study. $\mathrm{NaAsO}_{2}$ exposure induced significantly decreased cell proportions of G0/G1 phase and increased cell proportions of both $\mathrm{S}$ and G2M phase (Figure 3). This finding suggested that low-dose $\mathrm{NaAsO}_{2}$ exposure promoted cell cycle progression from $\mathrm{G} 1$ to $\mathrm{S} / \mathrm{G} 2 \mathrm{M}$ phase, which might explain the increased proliferation in $\mathrm{NaAsO}_{2}$ exposed $\mathrm{HaCat}$ cells. Inversely, treatment of MK2206 increased the cell proportions of G0/G1 phase and decreased the cell proportions of both $S$ and G2M phases in the $\mathrm{NaAsO}_{2}$ exposed cells (Figure 3), which suggested that cell cycle progression from G1 to S/G2M phase could be abolished by Akt inhibition. This result indicated that Akt played a role in the cell cycle regulation of $\mathrm{NaAsO}_{2}$ exposed HaCat cell.

\section{Repeated Low-Dose $\mathrm{NaAsO}_{2}$ Induced Phosphoraled Protein Expression of

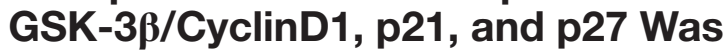 Regulated by Akt}

In order to further elucidate the mechanism of cell cycle progression, we focused on Akt and its downstream factors of GSK-3 $\beta /$ cyclinD1, p21, and p27, which were associated with cell cycle regulation (Figure 4A). Results of western blot analysis indicated that Akt could be fully activated by both of the two concentrations of $\mathrm{NaAsO}_{2}$ through phosphorylation at Ser 473. The phosphorylated activation could be attenuated by the treatment of MK2206 (Figure 4B). Along with the increase of $p$-Akt expression, GSK-3 $\beta$, one of the downstream factors of Akt, was found to be significantly phosphorylated at the Ser 9 site (Figure 4C). The expression of total cyclin D1 was also increased in the $\mathrm{NaAsO}_{2}$ exposed cells (Figure 4D), while the expression of $p$-cyclin D1 (Thr 286) was markedly decreased (Figure 4E). Treatment of MK2206 decreased the expression of $p$-GSK-3 $\beta$ (Ser 9) and total cyclin D1, but increased the expression of $p$-cyclin D1 (Thr 286) in the $\mathrm{NaAsO}_{2}$ exposed cells. Since cyclin D1 is one of the downstream factors of GSK-3 $\beta$ and phosphorylation of GSK-3 $\beta$ at Ser 9 results in the inactivation of its kinase capability which will lead to the decreased phosphorylation of cyclin D1 and the consequent increased level of total cyclin $\mathrm{D} 1$, our findings indicated that signaling pathway of Akt/ GSK-3 $\beta /$ cyclin D1 was involved in the cell cycle regulation of $\mathrm{NaAsO}_{2}$ exposed HaCat cells. 
$\mathbf{A}$

\section{$\mathrm{NaAsO}_{2}(\mu \mathrm{M})$}
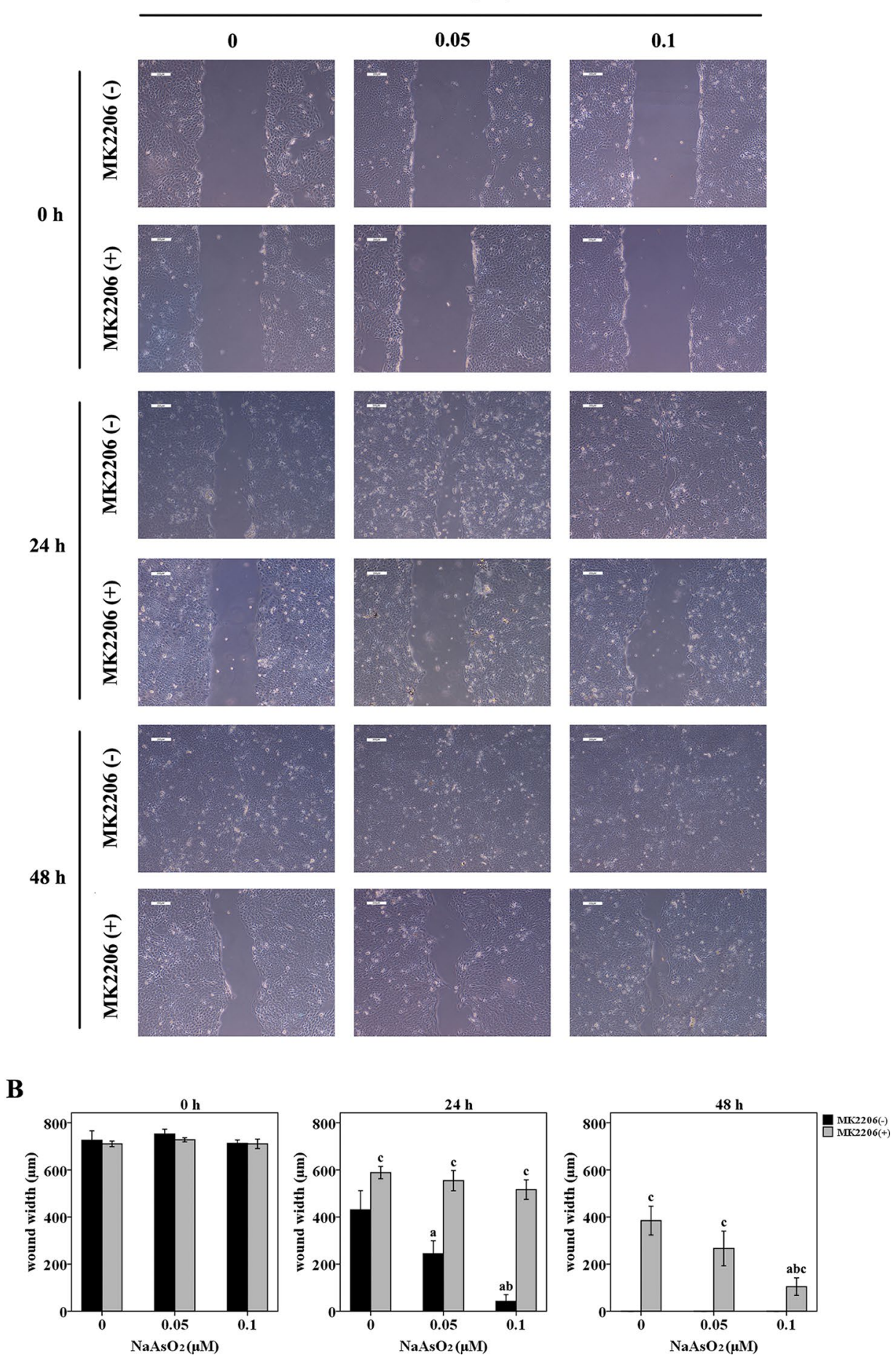

FIGURE 2 | Repeated low-dose $\mathrm{NaAsO}_{2}$ exposure increased the wound closure speed of HaCat cells. Cells were seeded into 6-well plates. The cell monolayers were scratched using a $200 \mu$ pipette tip to create a wound. Half of the cells were treated with MK2206 (10 $\mu$ mol/L). DMSO was added into the other half of the cells. Wound width was monitored over time by microscopy and photographed immediately at the time point of 0, 24 and 48 h after MK2206 treatment. (A) Images are the representative photos of three separate experiments. (B) Quantitation of wound width $(n=3)$. $\mathrm{NaAsO}_{2}$ exposure increased the wound closure speed, no matter in the presence or absence of MK2206. Although wound closure was inhibited by the treatment of $\mathrm{MK} 2206, \mathrm{NaAsO}_{2}$ exposed cells showed higher wound-healing capability than that of the control cells. Significant difference was defined as $p$ less than 0.05. a, vs. the corresponding $0 \mu \mathrm{M}$ group; b, vs. the corresponding $0.05 \mu \mathrm{M}$ group; $\mathrm{c}$, vs. the MK2206(-) group of the same $\mathrm{NaAsO}_{2}$ concentration. 
A

MK2206 (-)

MK2206 (+)
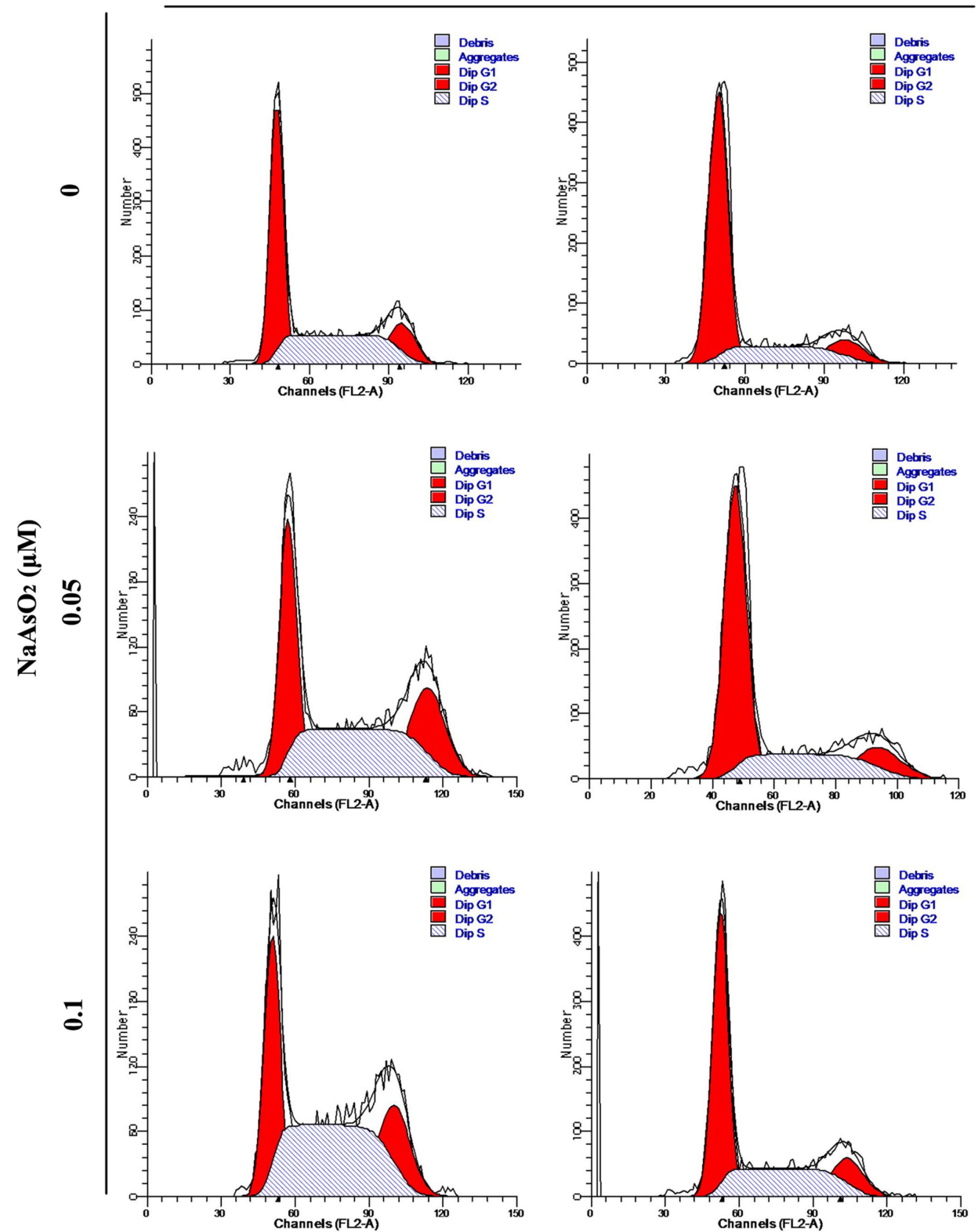

B
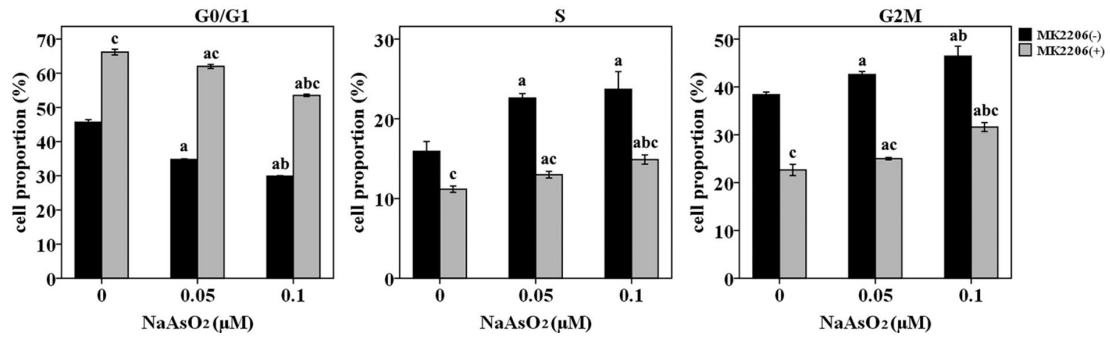

FIGURE 3 | Repeated low-dose $\mathrm{NaAsO}_{2}$ exposure promoted HaCat cell cycle progression from G0/G1 to S/G2M phase. Cell cycle was detected by the standard propidium iodide method. (A) Cell cycle analysis evaluated by flow cytometry. Images are the representative results of three separate experiments. (B) Quantitative graphs of the cell proportions divided by cell cycle $(n=3)$. $\mathrm{NaAsO}_{2}$ exposure resulted in decreased proportion of G0/G1 phase, but increased proportions of $\mathrm{S}$ and G2M phases, no matter in the presence or absence of $\mathrm{MK}_{2} 206$. $\mathrm{NaAsO}_{2}$ induced cell cycle progression from G0/G1 to S/G2M phase could be attenuated by the treatment of MK2206. Significant difference was defined as $p$ less than 0.05 . a, vs. the corresponding $0 \mu \mathrm{M}$ group; b, vs. the corresponding $0.05 \mu \mathrm{M}$ group; $\mathrm{c}$, vs. the MK2206(-) group of the same $\mathrm{NaAsO}_{2}$ concentration. 
A
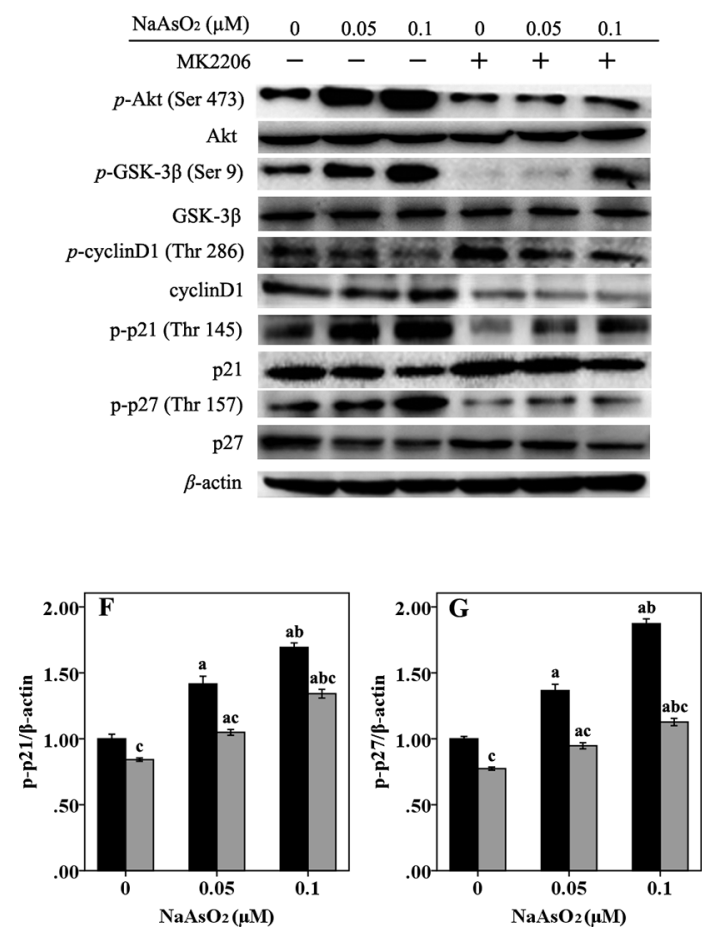
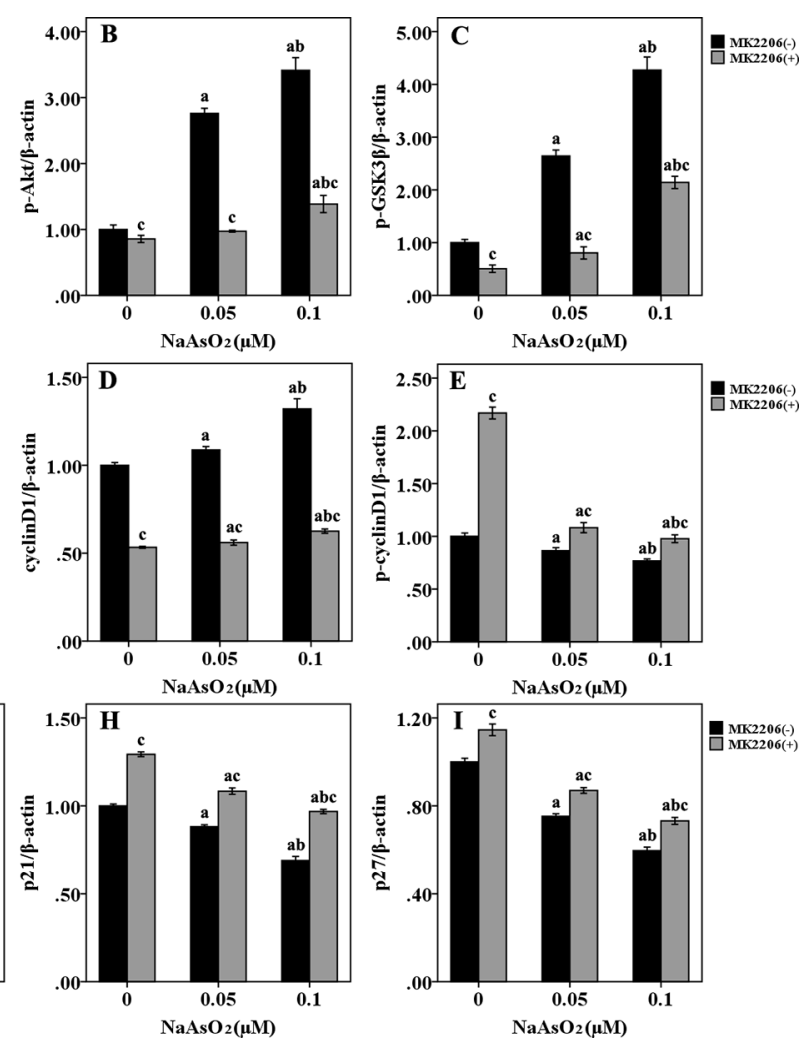

FIGURE 4 | Repeated low-dose $\mathrm{NaAsO}_{2}$ exposure induced phosphorylated protein expression of GSK-3ß/cyclinD1, p21 and p27 was regulated by AKT. Protein expression was detected by the Western blot analysis. (A) Images are the representative results of three separate experiments. Quantitative graphs $(n=3)$ showed the relative intensity of the target proteins compare with $\beta$-actin, including $p$-AKT (B), $p$-GSK-3 $\beta$ (C), total cyclin D1 (D), $p$-cyclin D1 (E), $p$-p21 (F), $p$-p27 (G), total p21 (H) and total p27 (I). $\mathrm{NaAsO}_{2}$ exposure induced increased expression of $p$-AKT, $p$-GSK-3 $\beta$, total cyclin D1, $p$-p21, and $p$-p27, but decreased expression of $p$-cyclin D1, total p21, and total p27. Treatment of MK2206 significantly reversed the expression of all of the above proteins. Significant difference was defined as $p$ less than 0.05. a, vs. the corresponding $0 \mu \mathrm{M}$ group; b, vs. the corresponding $0.05 \mu \mathrm{M}$ group; c, vs. the $\mathrm{MK}^{2} 206(-)$ group of the same $\mathrm{NaAsO}_{2}$ concentration.

p21 and p27, two main members of negative regulators of cell cycle, are also downstream factors of Akt, which are phosphorylated by Akt at Thr 145 and Thr 157, respectively. In the present study, along with the increased expression of p-Akt, the expression of both $p$-p21 (Thr 145) (Figure 4F) and p-p27 (Thr 157) (Figure 4G) was significantly increased in the $\mathrm{NaAsO}_{2}$ exposed cells. At the same time, the expression of total p21 (Figure 4H) and p27 (Figure 4I) was found to be decreased. Treatment of MK2206 markedly decreased the expression of both of the two phosphorylated proteins, but increased the expression of their total proteins. Since phosphorylation of these cell cycle inhibitors will lead to the cytoplasmic retention of these proteins and precluding their binding and inhibition of the cyclin/CDK complexes, our results suggested that the Akt regulated phosphorylation of p21 and p27 were also involved in the promotion of cell cycle progression from G1 to S/G2M phase in the $\mathrm{NaAsO}_{2}$ exposed $\mathrm{HaCat}$ cells.

\section{DISCUSSION}

Arsenic has been classified as a group 1 carcinogen by IARC. Although various hypotheses were proposed, it is as yet uncertain about the mechanism of arsenic induced carcinogenesis. Due to the weak mutagenic capability of arsenic, it is considered that the activation of signaling pathways and gene expression which play a role in the cell growth may function in the process of carcinogenesis (Bernstam and Nriagu, 2000). Some recent studies suggested that Akt signals which play an important role in cellular proliferation and survival were also involved in arsenic induced carcinogenesis (Carpenter and Jiang, 2013). Since much of the findings about Akt signals were obtained from the studies of acute arsenic exposure at relatively higher concentrations, studies about the effects of long-term exposure at lower dose is needed, considering the emerging facts that arsenic may increase the risk of cancers at lower levels that is not regarded as harmful before (Karagas et al., 2015; Carlin et al., 2016). Skin is the primary target organ of arsenic (Centeno et al., 2002). In addition, the main type of arsenic-related skin cancers is squamous cell carcinomas arising in keratosis (Yeh et al., 1968; Hunt et al., 2014). Therefore, we investigated the effects of long-term, low-dose arsenic exposure on Akt signals, particularly on its downstream factors participating in cell cycle regulation in human keratinocytes.

Several studies previously reported the effects of repeated low-dose arsenic exposure in HaCat cells. For example, Ouyang et al. (2008) found that repeated $\mathrm{NaAsO}_{2}$ exposure $(2.5 \mu \mathrm{M}$, 8 weeks) could induce the increased anchorage independent 
growth capacity in HaCat cells. Al-Eryani et al. (2017) reported that $\mathrm{NaAsO}_{2}$ exposure $(0.1 \mu \mathrm{M}, 7$ weeks $)$ resulted in differential gene expression which indicated the dysregulation of cell cycle control. Liu et al. (2015) proved that apart from the increase of cellular proliferation, low-dose $\mathrm{As}_{2} \mathrm{O}_{3}$ ( 0.1 and $0.2 \mu \mathrm{M}, 4$ weeks) exposure could also induce the malignant transformation of HaCat cells such as epithelial-to-mesenchymal transition, matrix metalloproteinases activation, and anchorageindependent growth.

The high concentration of $\mathrm{NaAsO}_{2}$ used in our study is $0.1 \mu \mathrm{mol} / \mathrm{L}$, which is comparable with the average blood arsenic levels of patients in Inner Mongolia, China where arsenic-related skin lesions are common (Pi et al., 2000). Cell proliferation and promotion of cell cycle progression from G1 to S/G2M phase could be induced not only by the high concentration, but also by the low concentration of $0.05 \mu \mathrm{mol} / \mathrm{L}$ in the present study. To our knowledge, it is the lowest concentration that have been reported up to now which could induce cell proliferation and cell cycle change upon repeated low-dose arsenic exposure.

MK2206 is an allosteric Akt kinase inhibitor. It binds to Akt and induces a conformational change in the Akt protein to the 'closed' cytoplasmic conformation which prevent its membrane translocation and phosphorylation that are necessary for its activation (Lindsley, 2010; Song et al., 2019). In this study, cell proliferation, cell cycle progression, and phosphorylated activation of Akt induced by $\mathrm{NaAsO}_{2}$ exposure could be attenuated by MK2206. These findings indicated that the phosphorylated activation of Akt and its consequent regulation through cell cycle were at least one of the reasons involved in the low-dose $\mathrm{NaAsO}_{2}$ induced cell proliferation.

Cyclin D1, which regulates the G1/S point of the cell cycle, is reported to be over expressed in many tumors (Casimiro et al., 2014). Overexpression of total cyclin D1 might be a consistent event during the carcinogenesis induced by arsenic exposure. It has been reported that signaling pathways including c-Jun/ AP-1 (Zhang et al., 2009), p38 MAPK (Liu et al., 2010), JNK/cJun (Li et al., 2011), and Erk1/2 (Liu et al., 2010; Huang et al., 2011) can be activated upon $\mathrm{NaAsO}_{2}$ exposure which results in the overexpression of total cyclin D1.

Activation of Akt signal was also reported to directly induce the overexpression of total cyclin D1 in several cell lines exposed to low-dose arsenicals within 12 to $48 \mathrm{~h}$. For example, Liu et al. (2010) reported that inhibiting the activation of Akt decreased the low-dose $\mathrm{As}_{2} \mathrm{O}_{3}(0.1 \mu \mathrm{mol} / \mathrm{L}, 24 \mathrm{~h})$ induced expression of total cyclin D1 in human breast epithelial cells (MCF10A). Ouyang et al. (2006) proved that low-dose $\mathrm{NaAsO}_{2}(5 \mu \mathrm{mol} / \mathrm{L}, 18$, 30 and $48 \mathrm{~h}$ ) induced overexpression of total cyclin D1 could be attenuated by the Akt inhibitors in mouse epidermal Cl41 cells. The group of Ouyang $(2007 ; 2008)$ also provided direct evidences that Akt played a role in the overexpression of total cyclin D1 in $\mathrm{HaCat}$ cells and normal human epidermal keratinocytes (NHEKs) upon low-dose $\mathrm{NaAsO}_{2}$ exposure (0.15-5 $\mu \mathrm{mol} / \mathrm{L}$, 12-48 h).

Although the relationship between Akt activation and total cyclin D1 overexpression upon low-dose arsenic treatment was confirmed by short time exposure, the evidences for long-term exposure were seldom reported. In our study, we continuously exposed $\mathrm{HaCat}$ cells by $\mathrm{NaAsO}_{2}$ for 15 weeks under the concentrations of 0.05 and $0.1 \mu \mathrm{mol} / \mathrm{L}$, and found that $\mathrm{NaAsO}_{2}$ induced overexpression of total cyclin D1 could be attenuated by MK2206. This result indicated that Akt was involved in the regulation of cyclin $\mathrm{D} 1$. In order to further reveal the linkage between Akt activation and cyclin D1 overexpression, we focused on the potential regulator of GSK-3 $\beta$, which is one of the downstream factors of Akt.

Recent reports indicated that Akt played a role in cell cycle progression partially by the phosphorylation at Ser 9 of GSK-3 $\beta$, which resulted in the inhibition of GSK-3 $\beta$ activity. While GSK-3 $\beta$ is a kinase responsible for the phosphorylation of cyclin D1 that results in its degradation (Cheung and Testa, 2013; Song et al., 2019), the phosphorylation of cyclin D1 at Thr 286 by GSK-3 $\beta$ could trigger nuclear-cytoplasmic translocation of cyclin D1, which could result in the ubiquitin mediated proteolytic degradation of cyclin D1 in the cytoplasm (Shimura, 2011).

In the present study, apart from the increased expression of p-Akt and total cyclin D1, we further found the corresponding increased expression of $p$-GSK-3 $\beta$ (Ser 9 ) and decreased expression of $p$-cyclin D1 (Thr 286). Treatment of MK2206 resulted in the decreased expression of $p$-Akt along with decreased expression of $p$-GSK-3 $\beta$ (Ser 9), increased expression of $p$-cyclin D1 (Thr 286), and decreased expression of total cyclin D1. Since the activity of GSK-3 $\beta$ is inhibited by Akt-dependent phophorylation at Ser 9 and GSK-3 $\beta$ mediated cyclin D1 protein degradation through phophorylating it at Thr 286, our findings suggested that the activation of Akt/GSK-3 $\beta$ signaling pathway was involved in the overexpression of cyclin D1, which might contribute to the cell cycle progression upon low-dose $\mathrm{NaAsO}_{2}$ exposure.

Cell cycle is mainly regulated by cyclins and the cyclin dependent kinases (CDKs). The cyclin inhibitor protein/ kinase inhibitor protein (Cip/Kip) family has the capability of inhibiting cyclin/CDK complex. p21 and p27 are two main members of Cip/Kip family, both of which could regulate the G1 check point of the cell cycle through binding to CDK/cyclin complexes (Starostina and Kipreos, 2012). The expression of p21 was reported to be decreased in HaCat cells upon longterm, low-dose $\mathrm{NaAsO}_{2}$ exposure, and dysfunction of p53 was suggested to be a possible mechanism (Komissarova and Rossman, 2010; Li et al., 2010). Decreased expression of p27 was also reported in cells chronically exposed to $\mathrm{NaAsO}_{2}$ which contributed to the proliferation of murine fibroblast cells (Trouba et al., 2000).

It has been suggested that the cell cycle inhibitors, p21 and p27, could be phosphorylated at Thr 145 and Thr 157, respectively, by Akt, which will lead to cytoplasmic retention of both of the proteins and finally prevent their binding and inhibition of the cyclin/CDK complexes (Cheung and Testa, 2013). In the present study, along with the decreased expressions of p21 and p27, we also found significantly increased expressions of $p$-p21 (Thr 145) and p-p27 (Thr 157) in the $\mathrm{NaAsO}_{2}$ exposed cells. The expression of both $p$-p21 (Thr 145) and $p$-p27 (Thr 157) could be attenuated by the treatment of MK2206. This finding indicated that the phosphorylation of p21 and p27 regulated by Akt also played a role in the cell cycle progression induced by low-dose $\mathrm{NaAsO}_{2}$ exposure. 
In our study, along with the increased proliferative capability and promotion of cell cycle progression, we also found increased expressions of MMP9 in the $\mathrm{NaAsO}_{2}$ exposed HaCat cells. MMP9 is one of the members of Matrix metalloproteinases (MMPs). MMPs are important mediators of alterations found in the microenvironment during carcinogenesis, which play an important role in extracellular matrix degradation, migration, and invasion. According to the recent reports, MMPs also play a role in regulating initial steps of carcinogenesis (Yadav et al., 2014). It has been reported that the activation of MMP9 contributes to the low-dose arsenic induced malignant transformation of HaCat cells (Pi et al., 2008). Treatment of MK2206 attenuated the expression of MMP9 in the $\mathrm{NaAsO}_{2}$ exposed cells of this study. This result indicated the role of Akt in regulating MMP9 activation in the long-term, low-dose $\mathrm{NaAsO}_{2}$ exposed $\mathrm{HaCat}$ cells. Some other reports also provided evidences of Akt-regulated MMP9 in the carcinogenesis (Wang F., et al., 2014; Cheng et al., 2019).

Finally, using data from only one transformed cell line (HaCat Keratinocytes) does not justify the overall effects of low dose $\mathrm{NaAsO}_{2}$ exposure on cell proliferation mediated by Akt signaling. This limited the findings of this study.

\section{CONCLUSIONS}

Taken together, our results suggested that the phosphorylative activation of Akt and its consequent phosphorylative regulation

\section{REFERENCES}

Al-Eryani, L., Waigel, S., Jala, V., Jenkins, S. F., and States, J. C. (2017). Cell cycle pathway dysregulation in human keratinocytes during chronic exposure to low arsenite. Toxicol. Appl. Pharmacol. 331, 130-134. doi: 10.1016/j. taap.2017.06.002

Bernstam, L., and Nriagu, J. (2000). Molecular aspects of arsenic stress. J. Toxicol. Environ. Health. B. Crit. Rev. 3 (4), 293-322. doi: 10.1080/109374000436355

Carlin, D. J., Naujokas, M. F., Bradham, K. D., Cowden, J., Heacock, M., Henry, H. F., et al. (2016). Arsenic and environmental health: state of the science and future research opportunities. Environ. Health Perspect. 124 (7), 890-899. doi: 10.1289/ehp.1510209

Carpenter, R. L., and Jiang, B. H. (2013). Roles of EGFR, PI3K, AKT, and mTOR in heavy metal-induced cancer. Curr. Cancer Drug Targets 13 (3), 252-266. doi: $10.2174 / 1568009611313030004$

Casimiro, M. C., Velasco-Velázquez, M., Aguirre-Alvarado, C., and Pestell, R. G. (2014). Overview of cyclins D1 function in cancer and the CDK inhibitor landscape: past and present. Expert. Opin. Investig. Drugs 23 (3), 295-304. doi: $10.1517 / 13543784.2014 .867017$

Celik, I., Gallicchio, L., Boyd, K., Lam, T. K., Matanoski, G., Tao, X., et al. (2008). Arsenic in drinking water and lung cancer: a systematic review. Environ. Res. 108 (1), 48-55. doi: 10.1016/j.envres.2008.04.001

Centeno, J. A., Mullick, F. G., Martinez, L., Page, N. P., Gibb, H., Longfellow, D., et al. (2002). Pathology related to chronic arsenic exposure. Environ. Health Perspect. 110 Suppl 5, 883-886. doi: 10.1289/ehp.02110s5883

Cheng, Y., Cheng, T., Zhao, Y., and Qu, Y. (2019). HMGAl exacerbates tumor progression by activating miR-222 through PI3K/Akt/MMP-9 signaling pathway in uveal melanoma. Cell Signal 63, 109386. doi: 10.1016/j. cellsig.2019.109386

Cheung, M., and Testa, J. R. (2013). Targets. Diverse mechanisms of AKT pathway activation in human malignancy. Curr. Cancer Drug 13 (3), 234-244. doi: $10.2174 / 1568009611313030002$ of its downstream cell cycle regulating factors of GSK-3 $\beta$ / cyclinD1, p21, and p27 played a role in the cell proliferation through the promotion of cell cycle progression from G1 to $\mathrm{S} / \mathrm{G} 2 \mathrm{M}$ phase in long-term, low-dose $\mathrm{NaAsO}_{2}$ exposed $\mathrm{HaCat}$ cells.

\section{DATA AVAILABILITY STATEMENT}

The datasets generated for this study are available on request to the corresponding author.

\section{AUTHOR CONTRIBUTIONS}

YC, XLiu, HW, SL, and NH carried out the experiments. YC drafted the manuscript. XLi conceived, designed, and supervised the experiments, and edited the manuscript. All authors contributed to revision and approved the manuscript.

\section{FUNDING}

This work was supported by the National Natural Science Foundation of China (NSFC) [grant number 81872568] and the Natural Science Foundation of Liaoning Province of China [grant number 20180550322].

Cohen, S. M., Arnold, L. L., Beck, B. D., Lewis, A. S., and Eldan, M. (2013). Evaluation of the carcinogenicity of inorganic arsenic. Crit. Rev. Toxicol. 43 (9), 711-752. doi: 10.3109/10408444.2013.827152

Hanada, M., Feng, J., and Hemmings, B. A. (2004). Structure, regulation and function of PKB/AKT - a major therapeutic target. Biochim. Biophys. Acta. 1697 (1-2), 3-16. doi: 10.1016/j.bbapap.2003.11.009

Huang, Y. C., Hung, W. C., Chen, W. T., Jiang, W. H., Yu, H. S., and Chai, C. Y. (2011). Effects of MEK and DNMT inhibitors on arsenic-treated human uroepithelial cells in relation to Cyclin-D1 and p16. Toxicol. Lett. 200 (1-2), 59-66. doi: 10.1016/j.toxlet.2010.10.015

Hunt, K. M., Srivastava, R. K., Elmets, C. A., and Athar, M. (2014). The mechanistic basis of arsenicosis: pathogenesis of skin cancer. Cancer Lett. 354 (2), 211-219. doi: 10.1016/j.canlet.2014.08.016

IARC Working Group on the Evaluation of Carcinogenic Risks to Humans. (2004). Some drinking-water disinfectants and contaminants, including arsenic. IARC Monogr. Eval. Carcinog. Risks Hum. 84, 1-477.

Karagas, M. R., Gossai, A., Pierce, B., and Ahsan, H. (2015). Drinking water arsenic contamination, skin lesions, and malignancies: a Systematic Review of the Global Evidence. Curr. Environ. Health Rep. 2 (1), 52-68. doi: 10.1007/ s40572-014-0040-x

Komissarova, E. V., and Rossman, T. G. (2010). Arsenite induced poly(ADPribosyl)ation of tumor suppressor P53 in human skin keratinocytes as a possible mechanism for carcinogenesis associated with arsenic exposure. Toxicol. Appl. Pharmacol. 243 (3), 399-404. doi: 10.1016/j.taap.2009.12.014

Li, Y., Ling, M., Xu, Y., Wang, S., Li, Z., Zhou, J., et al. (2010). The repressive effect of NF-kappaB on 53 by mot- 2 is involved in human keratinocyte transformation induced by low levels of arsenite. Toxicol. Sci. 116 (1), 174-182. doi: 10.1093/ toxsci/kfq109

Li, Y., Shen, L., Xu, H., Pang, Y., Xu, Y., Ling, M., et al. (2011). Up-regulation of cyclin D1 by JNK1/c-Jun is involved in tumorigenesis of human embryo lung fibroblast cells induced by a low concentration of arsenite. Toxicol. Lett. 206 (2), 113-120. doi: 10.1016/j.toxlet.2011.06.024 
Liao, W. T., Lan, C. C., Lee, C. H., and Yu, H. S. (2011). Concentration-dependent cellular responses of arsenic in keratinocytes. Kaohsiung. J. Med. Sci. 27 (9), 390-395. doi: 10.1016/j.kjms.2011.05.006

Lindsley, C. W. (2010). The Akt/PKB family of protein kinases: a review of small molecule inhibitors and progress towards target validation: a 2009 update. Curr. Top. Med. Chem. 10 (4), 458-477. doi: 10.2174/156802610790980602

Liu, Y., Hock, J. M., Sullivan, C., Fang, G., Cox, A. J., Davis, K. T., et al. (2010). Activation of the p38 MAPK/Akt/ERK1/2 signal pathways is required for the protein stabilization of CDC6 and cyclin D1 in low-dose arsenite-induced cell proliferation. J. Cell. Biochem. 111 (6), 1546-1555. doi: 10.1002/jcb.22886

Liu, Z. M., Tseng, H. Y., Yeh, B. W., Wu, W. J., and Huang, H. S. (2015). TG-interacting factor mediates arsenic-induced malignant transformation of keratinocytes via c-Src/EGFR/AKT/FOXO3A and redox signalings. Arch. Toxicol. 89 (12), 2229-2241. doi: 10.1007/s00204-014-1445-x

Ouyang, W., Li, J., Ma, Q., and Huang, C. (2006). Essential roles of PI-3K/Akt/ IKKbeta/NFkappaB pathway in cyclin D1 induction by arsenite in JB6 Cl41 cells. Carcinogenesis 27 (4), 864-873. doi: 10.1093/carcin/bgi321

Ouyang, W., Li, J., Zhang, D., Jiang, B. H., and Huang, D. C. (2007). PI-3K/Akt signal pathway plays a crucial role in arsenite-induced cell proliferation of human keratinocytes through induction of cyclin D1. J. Cell. Biochem. 101 (4), 969-978. doi: 10.1002/jcb.21279

Ouyang, W., Luo, W., Zhang, D., Jian, J., Ma, Q., Li, J., et al. (2008). PI-3K/Akt pathway-dependent cyclin D1 expression is responsible for arsenite-induced human keratinocyte transformation. Environ. Health Perspect. 116 (1), 1-6. doi: 10.1289/ehp. 10403

Pi, J., Kumagai, Y., Sun, G., Yamauchi, H., Yoshida, T., Iso, H., et al. (2000). Decreased serum concentrations of nitric oxide metabolites among Chinese in an endemic area of chronic arsenic poisoning in inner Mongolia. Free. Radic. Biol. Med. 28, 1137-1142. doi: 10.1016/S0891-5849(00)00209-4

Pi, J., Diwan, B. A., Sun, Y., Liu, J., Qu, W., He, Y., et al. (2008). Arsenicinduced malignant transformation of human keratinocytes: involvement of Nrf2. Free Radic. Biol. Med. 45 (5), 651-658. doi: 10.1016/j. freeradbiomed.2008.05.020

Rahman, M. M., Ng, J. C., and Naidu, R. (2009). Chronic exposure of arsenic via drinking water and its adverse health impacts on humans. Environ. Geochem. Health 31 Suppl 1, 189-200. doi: 10.1007/s10653-008-9235-0

Rodríguez-Lado, L., Sun, G., Berg, M., Zhang, Q., Xue, H., Zheng, Q., et al. (2013). Groundwater arsenic contamination throughout China. Science 341 (6148), 866-868. doi: 10.1126/science.1237484

Saint-Jacques, N., Parker, L., Brown, P., and Dummer, T. J. (2014). Arsenic in drinking water and urinary tract cancers: a systematic review of 30 years of epidemiological evidence. Environ. Health 13, 44. doi: 10.1186/1476-069X-13-44

Sale, E. M., and Sale, G. J. (2008). Protein kinase B: signalling roles and therapeutic targeting. Cell. Mol. Life. Sci. 65 (1), 113-127. doi: 10.1007/s00018-007-7274-9
Shimura, T. (2011). Acquired radioresistance of cancer and the AKT/GSK3 $\beta /$ cyclin D1 overexpression cycle. J. Radiat. Res. 52 (5), 539-544. doi: 10.1269/ jrr.11098

Song, M., Bode, A. M., Dong, Z., and Lee, M. H. (2019). AKT as a therapeutic target for cancer. Cancer Res. 79 (6), 1019-1031. doi: 10.1158/0008-5472. CAN-18-2738

Souza, K., Maddock, D. A., Zhang, Q., Chen, J., Chiu, C., Mehta, S., et al. (2001). Arsenite activation of P13K/AKT cell survival pathway is mediated by p38 in cultured human keratinocytes. Mol. Med. 7 (11), 767-772. doi: 10.1007/ BF03401967

Starostina, N. G., and Kipreos, E. T. (2012). Multiple degradation pathways regulate versatile CIP/KIP CDK inhibitors. Trends. Cell. Biol. 22 (1), 33-41. doi: $10.1016 /$ j.tcb.2011.10.004

Trouba, K. J., Wauson, E. M., and Vorce, R. L. (2000). Sodium arsenite-induced dysregulation of proteins involved in proliferative signaling. Toxicol. Appl. Pharmacol. 164 (2), 161-170. doi: 10.1006/taap.1999.8873

Wang, F., Xiao, W., Sun, J., Han, D., and Zhu, Y. (2014). MiRNA-181c inhibits EGFRsignaling-dependent MMP9 activation via suppressing Akt phosphorylation in glioblastoma. Tumour Biol. 35 (9), 8653-8658. doi: 10.1007/s13277-014-2131-6

Wang, W., Cheng, S., and Zhang, D. (2014). Association of inorganic arsenic exposure with liver cancer mortality: a meta-analysis. Environ. Res. 135, 120125. doi: 10.1016/j.envres.2014.08.034

Yadav, L., Puri., N., Rastogi, V., Satpute, P., Ahmad, R., and Kaur, G. (2014). Matrix metalloproteinases and cancer - roles in threat and therapy. Asian Pac. J. Cancer Prev. 15 (3), 1085-1091. doi: 10.7314/APJCP.2014.15.3.1085

Yeh, S., How, S., and Lin, C. (1968). Arsenical cancer of skin: histologic study with special reference to Bowen's disease. Cancer 21 (2), 312-339. doi: 10.1002/1097-0142(196802)21:2<312::AID-CNCR2820210222>3.0.CO;2-K

Yu, H. S., Liao, W. T., and Chai, C. Y. (2006). Arsenic carcinogenesis in the skin. J. Biomed. Sci. 13 (5), 657-666. doi: 10.1007/s11373-006-9092-8

Zhang, D., Li, J., Gao, J., and Huang, C. (2009). c-Jun/AP-1 pathway-mediated cyclin D1 expression participates in low dose arsenite-induced transformation in mouse epidermal JB6 Cl41 cells. Toxicol. Appl. Pharmacol. 235 (1), 18-24. doi: 10.1016/j.taap.2008.11.002

Conflict of Interest: The authors declare that the research was conducted in the absence of any commercial or financial relationships that could be construed as a potential conflict of interest.

Copyright (c) 2019 Chen, Liu, Wang, Liu, Hu and Li. This is an open-access article distributed under the terms of the Creative Commons Attribution License (CC $B Y)$. The use, distribution or reproduction in other forums is permitted, provided the original author(s) and the copyright owner(s) are credited and that the original publication in this journal is cited, in accordance with accepted academic practice. No use, distribution or reproduction is permitted which does not comply with these terms. 